\title{
ANALYSIS OF SURFACE CHANGES FROM UNDERMINING AND BUILDING SITE CATEGORIZATION: THE CASE STUDY IN MINING LOCATION LOUKY NEAR KARVINÁ
}

\author{
Hana DOLEŽALOVÁ ${ }^{1)}$ * and Vlastimil KAJZAR ${ }^{2)}$ \\ 1) Department of Environmental Geography, Institute of Geonics of the Czech Academy of Sciences, Drobného 28, \\ 60200 Brno, Czech Republic \\ 2) Department of Geomechanics and Mining Research, Institute of Geonics of the Czech Academy of Sciences, \\ Studentská 1768, 70800 Ostrava-Poruba, Czech Republic \\ *Corresponding author's e-mail: hana.dolezalova@ugn.cas.cz
}

\begin{tabular}{l}
\hline ARTICLE INFO \\
\hline Article history: \\
Received 2 December 2020 \\
Accepted 4 March 2021 \\
Available online 19 March 2021 \\
\hline
\end{tabular}

Keywords:

Coal mining

Surface movements and deformations

Building site categories

Upper Silesian Coal Basin

Karviná region

\begin{abstract}
Repeated geodetic observations were applied in mining location Louky near Karviná to detect surface changes from undermining in complex geo-mechanical conditions. Analyses of the subsidence magnitude and the length and direction of horizontal displacements showed that the subsidence trough was formed unevenly not only due to the position of the exploited local longwall panels and their different size but also showed a notable effect of the dominant tectonic fault. The significantly uneven development of the subsidence trough negatively affects line constructions. Terrain deformations of the road and stream pipeline were computed and classified into the building site categories according to the Czech standard ČSN 73 0039. The course of individual deformations in the monitored locality is influenced by a complex geo-mechanical situation. While the course of the subsidence curves is continuous at the observed pipeline and the classification of individual sections into building site categories corresponds with that, the road profile points out a more complex development of surface deformations. At the end of the observed period, $5 \%$ of the profiles' sections fell into category III (medium intensity), $49 \%$ into category IV (moderate intensity) and $32 \%$ stayed in category $\mathrm{V}$ (very moderate intensity of mining effects).
\end{abstract}

\section{INTRODUCTION}

Research on the processes accompanying coal mining had been led in geosciences worldwide in the past and it is still a topical issue nowadays, e.g. Perz, 1957; Hiramatsu et al., 1979; Whitaker and Reddish, 1989; Bräuner, 1994; Sheorey et al., 2000; Miller, 2011; Mark and Gauna, 2016; Muntean et al., 2016. As the origins of the systematic hard coal mining in the Upper Silesian Coal Basin (USCB) date back to the $18^{\text {th }}$ Century, its consequences were researched by a number of authors, the most important of which are: Knothe, 1953, 1984 and Neset, 1984 followed among others by Idziak, 1999; Perski and Jura, 1999; Schenk, 1999; Strzałkowski, 2001; Černý et al., 2003; Bogusz and Mendecki, 2011; Dulias, 2016. Although theories of the evaluation and prediction of surface changes from underground mining have been developed for many decades, the expected mining consequences in a specific locality cannot be fully described. Local geological and geo-mechanical conditions significantly affect the progression of the subsidence trough and the resulting movements and deformations of the surface. Tectonic faults may cause irregularities in mining subsidence and other surface changes, and the studies have shown that the effects of the faults on the ground movements differ, e.g. King et al., 1974; Kratzsch, 1983; Blachowski et al.; 2009, Jiránková, 2012; Wesolowski, 2016. Thus, only an in-situ measurement will capture the actual spatio-temporal surface changes caused by undermining in complex geo-mechanical conditions.

Undermined areas with ongoing deep mining are often actively used on the surface. Although residential and other buildings are usually demolished as a consequence of mining, the transport and technical infrastructure often has to serve further. These are mostly roads or other line constructions (water or steam pipelines) which can be damaged by surface movements and deformations caused by underground mining. In the case of multi-seam mining, the conditions for surface constructions may gradually deteriorate. Based on the size of individual surface deformations, it is possible to assess the intensity of mining impacts on constructions in the undermined area, according to the standard ČSN 730039 (2015), Design of constructions on the mining subsidence areas. The input values for the assessment of the intensity of undermining effects are the values of three surface deformations: horizontal strain $\varepsilon[\mathrm{mm} / \mathrm{m}]$, curvature (radius of curvature $R[\mathrm{~km}]$ ) and tilt of the terrain $i[\mathrm{~mm} / \mathrm{m}]$. These are usually computed from surveyed spatial coordinates of points fixed on surface constructions. The values of horizontal strain and tilt can also be measured directly with special devices (dilatometers, strain gauges, inclinometers). 
Terrain classification with respect to constructions in the USCB was introduced in the 1950s (Budryk and Knothe, 1956) and was subsequently developed in Poland by, e.g. Przybyła and Świądrowski, 1968; Sroka et al., 1994; Ostrowski and Ćmiel, 2008; Popiolek, 2009 and it is still topical today, when it is improved using modern methods, e.g. GIS (Malinowska and Hejmanowski, 2010), even a deformation information system to support and facilitate studies of mining-ground deformations was introduced (Blachowski et al., 2014b). Also in the Czech part of USCB this topic finds its place both for determination of hazard zones (Lamich et al., 2016) and land use planning (Marschalko et al., 2011).

In the example of a newly forming subsidence trough in the mining locality Louky near Karviná in the Czech part of the USCB, the aim of the presented research was to capture real spatio-temporal surface changes associated with underground mining, i.e. surface movements (subsidence and horizontal displacement) and deformations (horizontal strain, curvature and tilt), and to detect the degree of influence of the complex geo-mechanical conditions using modern geodetic and geo-information technologies. The surveying, carried out in 2006-2011, was based on a combination of direct and indirect surveying techniques, in particular the global navigation satellite system (GNSS) supplemented by remote sensing methods and other geodetic and geophysical techniques. The obtained datasets were subsequently evaluated in the context of geological and geo-mechanical conditions, advance of longwall mining and predicted surface changes.

Other research on mining subsidence and accompanying surface changes caused by undermining has been led worldwide (e.g. Can et al., 2012; Chen et al., 2020) but rarely the surveying has been used to obtain spatial coordinates of such a large amount of surface points repeatedly for several years. In this paper, we first summarize the knowledge gained from the evaluation of the surface movements in the Louky locality, partially published, e.g. in Staš et al., 2009; Doležalová et al., 2009; Doležalová et al., 2010; Doležalová, 2011; Kajzar et al., 2011; Doležalová et al., 2012; Kadlečík et al., 2015; Doležalová and Kajzar, 2017; Kajzar, 2018. Then, as a main part of the paper, we extend our analysis to the surface deformations caused by multiple undermining in the area with complex geo-mechanical conditions and classify individual sections of the monitored line structures into building site categories according to the values of horizontal strain, radius of curvature and tilt of the terrain.

\section{SURFACE DEFORMATIONS FROM UNDERMINING}

The movement of a point on the surface of an undermined area is a general movement towards the center of gravity of the exploited mass. This general movement consists of two components: a vertical movement a subsidence - and a horizontal movement - a displacement. From these movements, surface deformations are derived: horizontal strain, tilt and curvature (Schenk, 1999).

Horizontal strain results from the mutual displacement of two surface points. It is either compression, when adjacent points approach each other, or extension, when these points move away from each other. Thus, the horizontal strain is given by the ratio of the change in the distance of two points over a time period to their original distance. From the surveyed coordinates of both points, the horizontal strain is calculated from (1) as:

${ }^{t} \varepsilon_{i, i+1}=\frac{{ }^{t} l_{i, i+1}-{ }^{0} l_{i, i+1}}{{ }^{0} l_{i, i+1}} 10^{3}=\left(\sqrt{\frac{\left({ }^{t} x_{i+1}-{ }^{t} x_{i}\right)^{2}+\left({ }^{t} y_{i+1}-{ }^{t} y_{i}\right)^{2}}{\left({ }^{0} x_{i+1}-{ }^{0} x_{i}\right)^{2}+\left({ }^{0} y_{i+1}-{ }^{0} y_{i}\right)^{2}}}-1\right) 10^{3}$

where

${ }^{t} \varepsilon_{i, i+1} \quad$ is the horizontal strain of the line section between points $P_{i}$ and $P_{i+1}$ in time $t$,

${ }^{0} l_{i, i+1}$

${ }^{t} l_{i, i+1}$

${ }^{0} x_{i},{ }^{0} y_{i}$

${ }^{t} x_{i},{ }^{t} y_{i}$

${ }^{0} x_{i+1},{ }^{0} y_{i+1}$ are the coordinates of point $P_{i+1}$ at the beginning,

${ }^{t} x_{i+1},{ }^{t} y_{i+1}$ are the coordinates of point $P_{i+1}$ in time $t$.

is the distance between points $P_{i}$ and $P_{i+1}$ at the beginning,

is the distance between points $P_{i}$ and $P_{i+1}$ in time $t$,

are the coordinates of point $P_{i}$ at the beginning,

are the coordinates of point $P_{i}$ in time $t$

Tilt as a local terrain declination caused by a different subsidence of two surface points is calculated from (2) as:

$t_{i_{i, i+1}}=\frac{{ }^{t} s_{i+1}-{ }^{t} s_{i}}{{ }^{0} l_{i, i+1}}=\frac{\left({ }^{t} z_{i+1}-{ }^{0} z_{i+1}\right)-\left({ }^{t} z_{i}-{ }^{0} z_{i}\right)}{\sqrt{\left({ }^{0} x_{i+1}-{ }^{0} x_{i}\right)^{2}+\left({ }^{0} y_{i+1}-{ }^{0} y_{i}\right)^{2}}}$

where

${ }^{t} i_{i, i+1} \quad$ is the tilt of the line section between points $P_{i}$ and $P_{i+l}$ in time $t$,

${ }^{t} s_{i} \quad$ is the subsidence of point $P_{i}$ in time $t$,

${ }^{t} s_{i+1} \quad$ is the subsidence of point $P_{i+1}$ in time $t$,

${ }^{0} l_{i, i+1} \quad$ is the distance between points $P_{i}$ and $P_{i+1}$ at the beginning,

${ }^{0} x_{i},{ }^{0} y_{i},{ }^{0} z_{i}$ are the coordinates of point $P_{i}$ at the beginning, 
${ }^{t} z_{i} \quad$ is the coordinate of point $P_{i}$ in time $t$,

${ }^{0} x_{i+1},{ }^{0} y_{i+1},{ }^{0} z_{i+1}$ are the coordinates of point $P_{i+1}$ at the beginning,

${ }^{t} z_{i+1} \quad$ is the coordinate of point $P_{i+1}$ in time $t$.

The surface curvature in the subsidence trough is caused by a different subsidence of three surface points. It is expressed by the radius of curvature $R$ which is defined as the reciprocal of the curvature $\rho: R=\rho^{-1}$. The radius of curvature $R$ is determined by calculating from subsidence of three points lying in a straight line. These points interlace in the vertical plane of the circle whose radius corresponds to the radius of curvature $R$.

$$
\begin{array}{r}
{ }^{t} R_{i, i+1, i+2}=\frac{{ }^{0} l_{i, i+1}+{ }^{0} l_{i+1, i+2} \frac{1}{2} \frac{{ }^{t} \delta_{i+1, i+2}-{ }^{t} \delta_{i, i+1}}{2}}{=} \\
\frac{\sqrt{\left({ }^{0} x_{i+1}-{ }^{0} x_{i}\right)^{2}+\left({ }^{0} y_{i+1}-{ }^{0} y_{i}\right)^{2}}+\sqrt{\left({ }^{0} x_{i+2}-{ }^{0} x_{i+1}\right)^{2}+\left({ }^{0} y_{i+2}-{ }^{0} y_{i+1}\right)^{2}}}{2\left({ }^{t} i_{i+1, i+2}-{ }^{t} i_{i, i+1}\right)}
\end{array}
$$

where

${ }^{t} R_{i, i+1, i+2}$ is the radius of curvature for points $P_{i}, P_{i+1}$ and $P_{i+2}$ in time $t$,

${ }^{0} l_{i, i+1}$ is the distance between points $P_{i}$ and $P_{i+l}$ at the beginning,

${ }^{0} l_{i+1, i+2} \quad$ is the distance between points $P_{i+1}$ and $P_{i+2}$ at the beginning,

${ }^{t} \delta_{i, i+1}$ is the tilt angle between points $P_{i}$ and $P_{i+1}$ in time $t$,

${ }^{t} \delta_{i+1, i+2} \quad$ is the tilt angle between points $P_{i+1}$ and $P_{i+2}$ in time $t$,

${ }^{t} i_{i, i+1}$ is the tilt of the line section between points $P_{i}$ and $P_{i+1}$ in time $t$,

${ }^{t} i_{i+1, i+2} \quad$ is the tilt of the line section between points $P_{i+1}$ and $P_{i+2}$ in time $t$,

${ }^{0} x_{i},{ }^{0} y_{i} \quad$ are the coordinates of point $P_{i}$ at the beginning,

${ }^{0} x_{i+1},{ }^{0} y_{i+1}$ are the coordinates of point $P_{i+1}$ at the beginning,

${ }^{0} x_{i+2},{ }^{0} y_{i+2}$ are the coordinates of point $P_{i+2}$ at the beginning.

Based on the size of individual deformations, the given part of the undermined area is classified into one of the 5 building site categories as an area with very moderate (V), moderate (IV), medium (III), intensive (II) or very intensive (I) intensity of mining impacts according to standard ČSN 730039 (see Table 1). The classification is determined by the least favorable value of the terrain deformation parameter.

\section{LOUKY LOCALITY}

The observed Louky locality lies in the Czech part of the USCB close to the town Karviná in the northeast of the Czech Republic, in the mining area of the ČSM-North colliery and it occupies about $6 \mathrm{~km}^{2}$. The region is associated with the hard coal mining since the $18^{\text {th }}$ Century. Total area of about $260 \mathrm{~km}^{2}$ is significantly disturbed by mining activities and it is estimated that the total subsidence exceeds $40 \mathrm{~m}$ in several parts of the region (Černý et al., 2003).

Originally, there was a village in the Louky locality but the buildings were demolished due to the undermining. Today, it is an unsettled mining landscape. The surface is flat to slightly undulating, most of it consists of agricultural and semi-natural areas along with the subareas designed to deposit mine spoils, some parts of the locality are flooded. A landscape reclamation took place here. The mining was active not only in the Louky locality but also in its environs (Fig. 1).

The first mining period in this area lasted from 1991 to 1999, with the extraction of horizontal longwall panels in several coal seams using the longwall mining with controlled caving system. While the northern part of

Table 1 Building site categories of the undermined area based on surface deformation parameters, according to standard ČSN 730039.

\begin{tabular}{cccc}
\hline Undermined area & \multicolumn{3}{c}{ Deformation } \\
\hline Building site category & $\begin{array}{c}\text { Horizontal strain } \\
\boldsymbol{\varepsilon}[\mathbf{m m} / \mathbf{m}]\end{array}$ & $\begin{array}{c}\text { Radius of curvature } \boldsymbol{R} \\
{[\mathbf{k m}]}\end{array}$ & $\begin{array}{c}\text { Tilt } \boldsymbol{i} \\
{[\mathbf{m m} / \mathbf{m}]}\end{array}$ \\
\hline I & $\varepsilon>7$ & $\mathrm{R}<3$ & $\mathrm{i}>10$ \\
II & $7 \geq \varepsilon>5$ & $3 \leq \mathrm{R}<7$ & $10 \geq \mathrm{i}>8$ \\
III & $5 \geq \varepsilon>3$ & $7 \leq \mathrm{R}<12$ & $8 \geq \mathrm{i}>5$ \\
IV & $3 \geq \varepsilon>1$ & $12 \leq \mathrm{R}<20$ & $5 \geq \mathrm{i}>2$ \\
V & $1 \geq \varepsilon$ & $\mathrm{R} \geq 20$ & $2 \geq \mathrm{i}$ \\
\hline
\end{tabular}




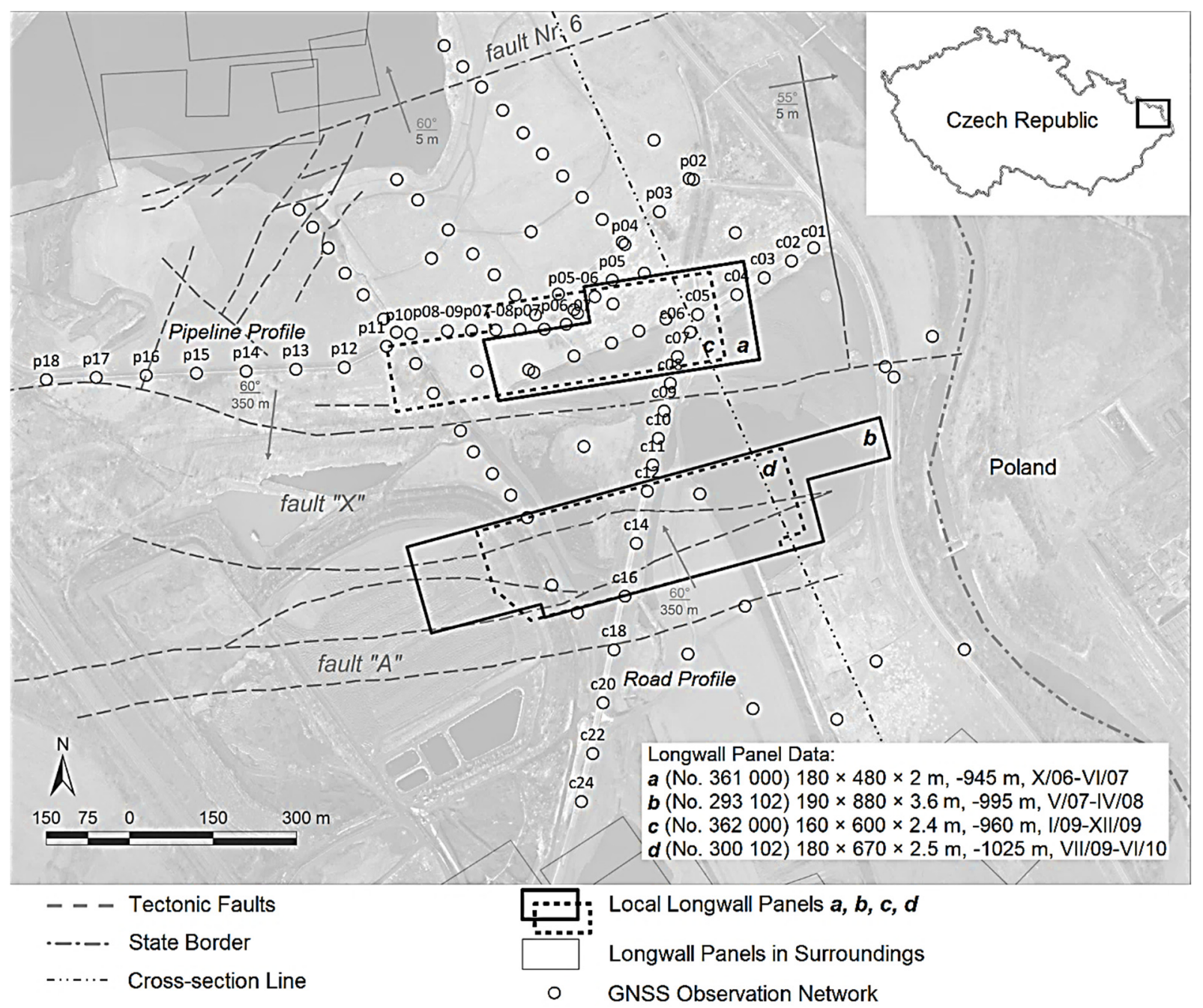

Fig. 1 The Louky locality and its environs.

the area was less disturbed by the exploitation in 3 coal seams, the southern part was disturbed significantly due to the exploitation in 7 coal seams.

The subsequent mining period lasted from 2006 to 2010 and there were 4 horizontal longwall panels exploited (Fig. 1). Data on these local longwall panels provided by the mining company are shown in Figure 1 (OKD, a.s., 2010). The exploitation was led from the east to the west.

The rock mass comprises upper carboniferous molasse sediments of mostly coal-bearing siliciclastic continental deposits. The USCB is split into tectonic blocks by normal faults with amplitude ranging from tens to hundreds of meters (Doležalová et al., 2012 after Dopita et al., 1997). In the Louky locality, 4 tectonic faults occur (Fig. 1). Dominant normal faults $A$ and $X$ pass sub-parallel to the local longwall panels. Fault $A$ is located southwards to local longwall panels $b$ and $d$ and it deflects from the observed locality. Fault $X$ lies in the overburden of northern local longwall panels $a$ and $c$, between the pairs of the local longwall panels ( $a, c$ and $b, d)$, and so the southern local longwall panels $b$ and $d$ lie in the wedge between tectonic faults $A$ and $X$. Both tectonic faults $A$ and $X$ have the amplitude $350 \mathrm{~m}$ and $\operatorname{dip} 60^{\circ}$ but an opposite orientation. Tectonic fault $X$ has the deformation zone thickness $25-50 \mathrm{~m}$, fault $A$ has a significantly thicker fault zone. Minor tectonic fault No. 6 is located in the north passing roughly in the east-west direction and another tectonic fault (unnamed) occurs in the east passing in the northsouth direction (Doležalová et al., 2012). A simplified vertical cross-section is presented in Figure 2 while its position in the area of interest is depicted in Figure 1.

\section{GNSS SURVEYING}

An extensive observation network of fixed points was created on the surface of the study area in 2006, some points were added during 2007 and 2008. Unfortunately, the points could not be fixed in a regular network due to the local conditions and the ongoing landscape reclamation. The points were primarily fixed in profiles and the network was thickened with scattered points where possible. As the points could not be fixed as massive markers or monuments in such area, they were either nailed into 


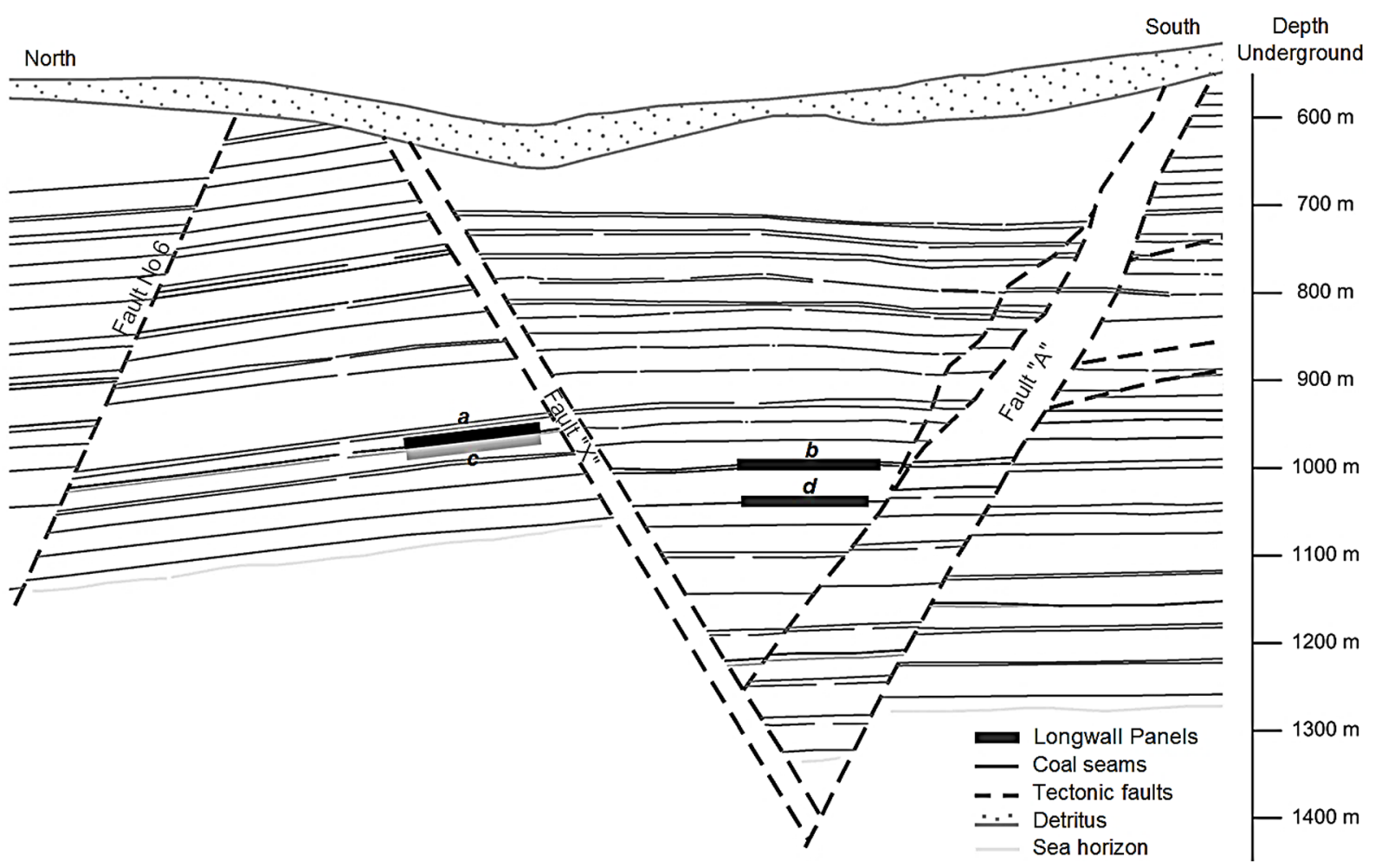

Fig. 2 The simplified cross-section of the Louky locality (modified after Kajzar, 2018).

the roadsides, or hammered into the ground as one meter steel bars. Also, some of the national network's trig points and benchmarks were observed, and marked points on the stream pipeline supporting frame were monitored using a customized GNSS antenna holder. Thus, a network of over 100 points was created, yet some of the points were destroyed, covered with mine spoils or flooded during the research.

Several options of surveying with Leica GPS System 1200 were tested and it was decided to use the rapid static method that is more accurate even though it is more time consuming than real time methods. The reference point was situated on a stable trigonometric point of a national network in the town of Karviná. GNSS surveying was repeated once a month in the first three years, later the interval was prolonged. In total, there were 41 GNSS campaigns surveyed in 91 days from 2006 to 2011. The raw data from the GNSS observations were post-processed in Leica GeoOffice software where the spatial coordinates of individual points were computed in WGS- 84 and in local S-JTSK coordinate systems (the transformation was based on a local transformation key that was prepared from the surrounding trig points of the national network with coordinates in both systems). As significant surface changes were expected in the monitored locality, the GNSS method was considered sufficient in terms of accuracy, which is claimed by the manufacturer as $0.005 \mathrm{~m}+0.5 \mathrm{ppm}$ in the horizontal position of a point and $0.010 \mathrm{~m}+0.5 \mathrm{ppm}$ in the vertical position of a surveyed point (Leica, 2007).

\section{ADDITIONAL METHODS}

To capture the surface changes of the whole area, the aerial photogrammetry was selected as an additional geodetic method (Kajzar et al., 2011). It was applied three times to capture the surface about $2.5 \times 2.5 \mathrm{~km}$ once a year from 2007 to 2009 when the major changes and surface adjustments were expected according to the mining and landscape reclamation plan. The resulting raw data included spatial coordinates of surface points in a grid of $20 \times 20 \mathrm{~m}$ and significant terrain edges. Analysis of the results of aerial photogrammetry made it possible to evaluate surface changes even in places where the fixed points were missing, and thus to find out not only the magnitude of subsidence but also the extent of the mine spoil deposits in these parts of the monitored locality.

To enrich the research, additional data from the remote sensing method (InSAR) were used (Kadlečík et al., 2015) and the data from the geophysical, geomechanical and classical geodetic monitoring were also implemented (Kajzar, 2018; Kajzar and Doležalová, 2013). However, discussion of these methods goes beyond the scope of this paper. The time periods of all the performed monitoring and surveying methods are schematically visualized together with mining of longwall panels $a, b, c$ and $d$ in Figure 3 . 


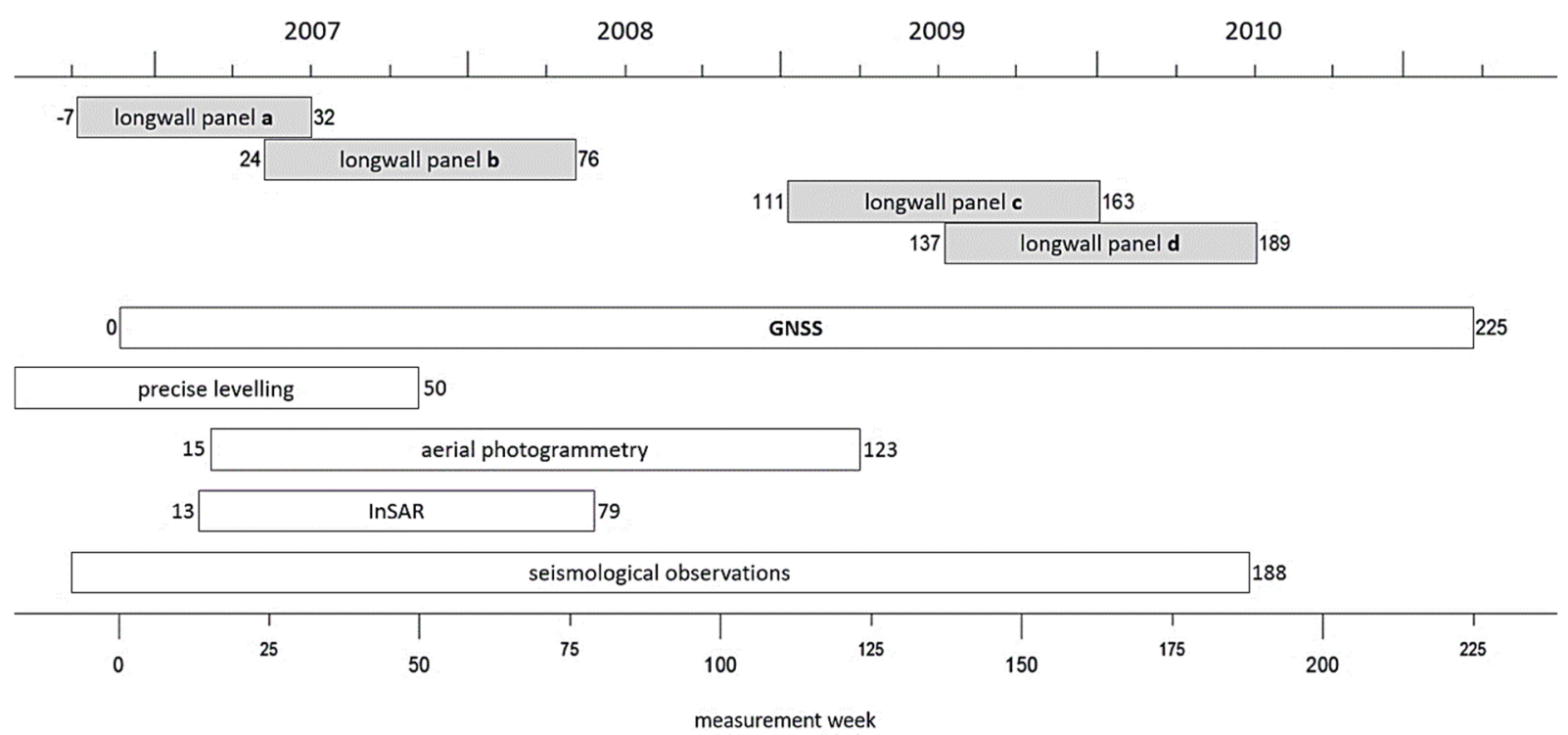

Fig. 3 Time periods of all the types of applied surveying with the exploitation of longwall panels.

\section{ANALYSES OF SURFACE MOVEMENTS}

The data obtained from the GNSS method were used as a suitable input information for the analysis of surface changes in the observed area. An effective work with the obtained data was allowed by modern geo-information software customized by the originally build tools (scripts, macros, extensions, applications) for new procedures of processing and evaluation. These tools then allowed spatial analyses with the acquired datasets such as: analysis of point subsidence and horizontal displacements development in time (Doležalová et al., 2010); analysis of the time- dependence of surface changes on the progress of exploitation (Doležalová et al., 2012); modelling of spatio-temporal surface development (Kajzar, 2012); comparison with official calculated predictions (Doležalová et al., 2009); prognosis of future subsidence development (Doležalová and Kajzar, 2017), etc. These procedures revealed the range, size and nature of the surface changes that were developed while the subsidence trough was formed as a result of multiple undermining. The odd behavior of the surface points, which was detected in some subareas of the Louky locality, points out complexity of the processes that accompany the mining activities in complex geo-mechanical conditions.

The arrangement of the fixed network enabled to analyze the surface movements of individual points, several profiles and the entire locality. The subsidence analyzed in surface models revealed magnitude of the vertical changes and extend of the subsidence trough in the monitored area but there was a distortion in the parts where the fixed points were missing (Doležalová et al., 2009; Doležalová et al., 2010). This is why the method of aerial photogrammetry was used as a complementary method to detect the surface changes. Analysis of the results of aerial photogrammetry made it possible to detect surface changes in all the parts of the locality and even in the surroundings, and thus to determine not only the magnitude of subsidence but also the size of mine spoil deposits. The method has defined an extent of the covered subareas and has shown that the surface of the Louky mining locality changes not only due to undermining but also due to mine spoil depositing and land reclamation. The differential models showed that the spoil deposits reached up to $11 \mathrm{~m}$ between 2007 and 2009 (see Kajzar et al., 2011 for details).

Graphs were prepared to analyze the subsidence of the points in various profiles. Figure 4A depicts a profile of points that were fixed as nails in the roadside. This profile passes from the east to the south across both major tectonic faults and above the eastern part of northern local longwall panels $a$ and $c$ and then above the central part of southern local longwall panels $b$ and $d$ (Fig. 1). The graph shows irregular progression of the subsidence curves, significant difference in the subsidence of nearby points and also almost identical subsidence of other points. This reflects a different influencing of the surface in different parts of the monitored area. A smoother progression of the subsidence curves can be seen on the pipeline profile in Figure 5A. This profile is made up of points surveyed on the frame of a stream pipeline and it passes from east to west along the projection of the edge of the northern local longwall panels $a$ and $c$ (Fig. 1). The graph shows quite regular course of the subsidence curves without any sudden changes.

As the land subsidence is the most obvious indicator of undermining, in many cases the subsidence trough is only monitored by measuring heights using the geodetic method of levelling. But analyses of the horizontal displacement length and its direction effectively complement the evaluation of 


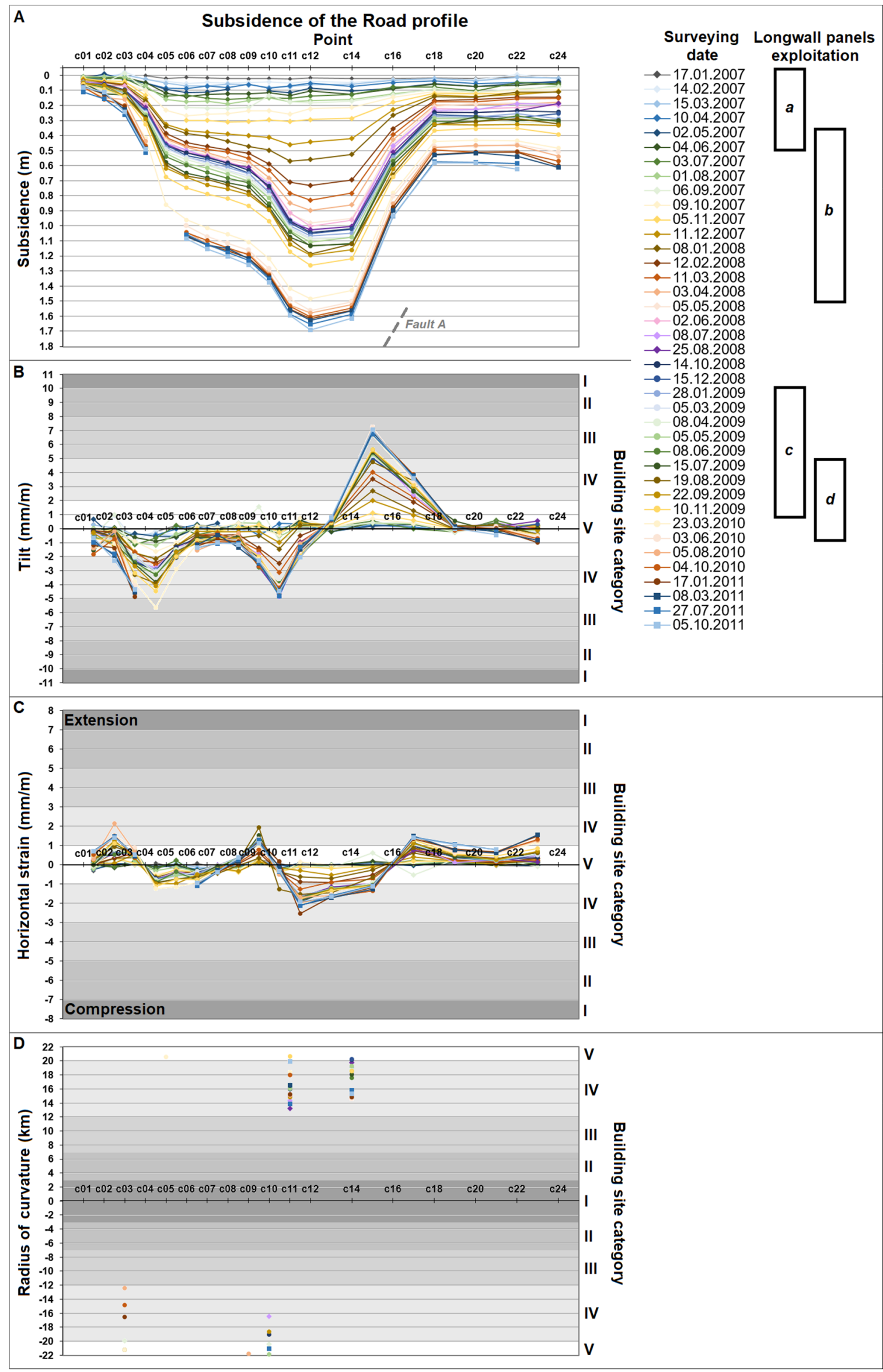

Fig. 4 A) Measured values of the subsidence on the road profile; B-D) Values of deformations of the individual line sections on the road profile and building site categories. 


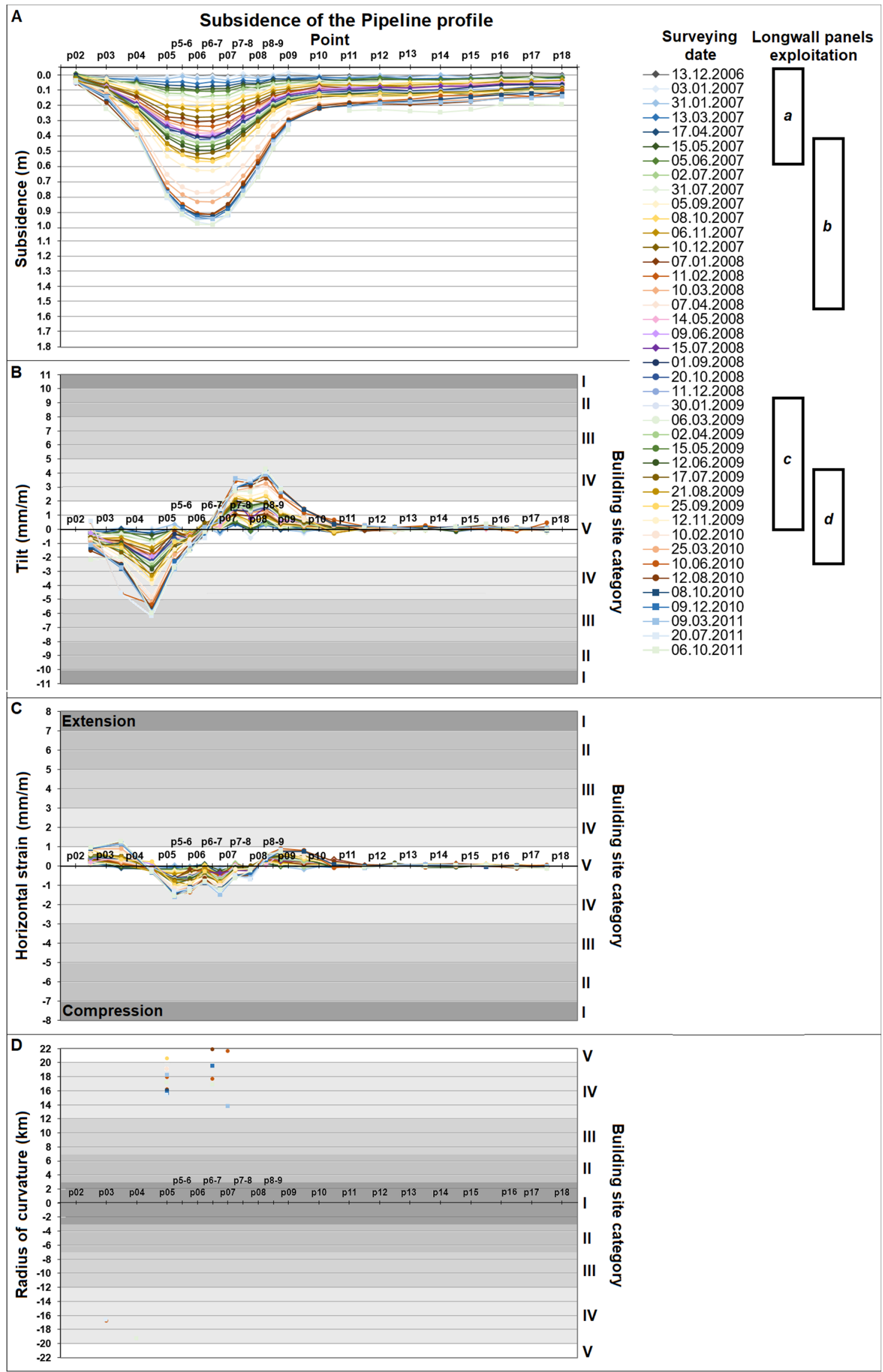

Fig. 5 A) Measured values of the subsidence on the pipeline profile; B-D) Values of deformations of the individual line sections on the pipeline profile and building site categories. 
surface changes. That is why for each point, its subsidence progression, horizontal displacement length and its direction was analyzed with respect to the point's position in the subsidence trough and its distance from the progressing coalfaces, to see dynamics of the movement and the reaction of the surface point to the approaching coalfaces. It was proved that the southern points were not affected by mining of the monitored local longwall panels but their general movement tended southwards as they were primarily influenced by exploitation outside the Louky locality (Doležalová et al., 2010 and Doležalová et al., 2012). Analyses of the subsidence magnitude and the length and direction of horizontal displacements from the GNSS data showed that the subsidence trough was formed unevenly not only due to the position of the four mined local longwall panels and their different size but also showed a notable effect of the dominant tectonic fault $A$. It forms a natural barrier here and the points lying south to the projection of this fault are shielded from mining influences from the exploitation of the local mining panels. These points are primarily affected by the mining activities to the south of the monitored locality (Doležalová et al., 2012).

The significant role of the major tectonic fault $A$ is most evident on the subsidence curves of the road profile. The graph of the subsidence of the points in the road profile (Fig. 4A) shows irregularities. The southern points of the profile (points c18 to c24) show almost uniform subsidence, in both magnitude and time, while the previous points' subsidence differs significantly. The difference in the total subsidence of points $\mathrm{c} 14$ and $\mathrm{c} 18$ is over $1 \mathrm{~m}$ at distance of $200 \mathrm{~m}$ while the difference in the subsidence of points c18 and $\mathrm{c} 22$ is $4 \mathrm{~cm}$ only at distance of $190 \mathrm{~m}$. Analyses of both subsidence and horizontal displacement of individual points in this part of the area confirmed an odd behavior of these close points. While there was an evident response of the points that lie northwards to point $\mathrm{c} 18$ to the approaching local coalfaces during individual mining phases, point $\mathrm{c} 18$ and the points lying southwards to c18 show minimal or none reaction to the longwall mining in the Louky locality. Such unusual behavior is in contradiction with the general theory of the bowl shape of the subsidence trough (Neset, 1984). The points lying southwards to point $\mathrm{c} 18$, not only those on the road profile but also other surveyed southern points, do not tend to move to the north, i.e. to the exploited local longwall panels. The plotting of the horizontal displacements showed that these points are not significantly affected by the mining processes in the Louky locality but the resulting trajectory is determined by the exploitation in the south. Analyses of vertical movements, detected from the aerial photogrammetry, revealed significant subsidence of more than $1.5 \mathrm{~m}$ in the south (outside the Louky locality) that is decisive for the behavior of these points (detailed information on the data and processing methodology of aerial images was published in Kajzar et al. (2011). The border between the part of the surface that is influenced by the local mining in the Louky locality and the part that is influenced by the extraction of longwall panels in the south copies the projection of tectonic fault $A$. Analyses of both vertical and horizontal movements proved the significant influence of this dominant tectonic fault forming a barrier which causes that the surface points lying to the south are not exposed to the consequences of mining of the local longwall panels while they change their spatial position due to the longwall mining in the south (Doležalová et al., 2012).

If it was only the amount of the extracted coal mass in the south that would be decisive for the behavior of points c18 to c24 and the effect of the tectonic fault would not be included, the subsidence profile would look different. Points c18 to c 24 would not subside almost identically, but with their position closer to the south, the subsidence would increase again from a certain profile point. This assumption is confirmed by the prediction model of the subsidence trough (Fig. 6).

Figure 6 shows the comparison of the prediction model of the surface subsidence in the Louky locality in the years 2007 and 2008 with the values surveyed at the end of this period $(12 / 2008)$ on the road profile. The prediction model was created by the mining company as the official basis for assessment of the consequences of undermining, using the BudrykKnothe theory (Doležalová et al., 2009). This prediction model takes into account all mining in 2007 and 2008 , i.e. not only the extraction of local longwall panels $a$ and $b$ in the Louky locality but also exploitation in its environs. The predicted subsidence curve of the road profile shows the influence on the southern points by mining activities in the south. According to this prediction, point $\mathrm{c} 22$ is at the interface of the effects of both mining fields and point c24 is apparently primarily affected by the mining in the south. However, the measured data confirms the complexity of the surface manifestations of undermining in areas with significant tectonic faults. The trend of the subsidence curve that was created from the GNSS data surveyed in 12/2008 differs significantly in the parts where the tectonic fault $A$ affects the surface most.

The evaluation of the horizontal displacement directions revealed that also the points on the north- west and west (including the western points of the pipeline profile) do not tend towards the local longwall panels and they are rather affected by the extraction in the surroundings (Doležalová et al., 2010). But here, the points' reaction is proportional to their distance from the local longwall panels. Points to the west gradually turn due to influencing from external mining. Also, from the subsidence analysis (Fig. 5A), we can see that there is no significant and sudden change in behavior of the surface points in this 


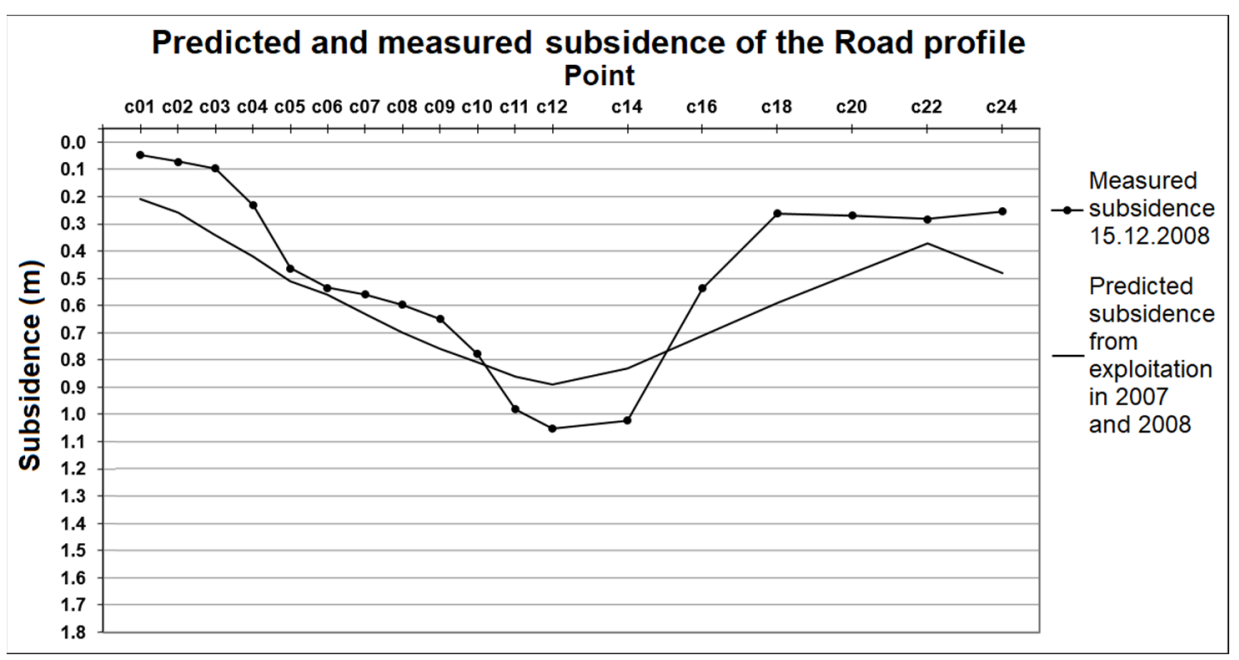

Fig. 6 Predicted and measured subsidence of the road profile (modified after Doležalová et al., 2009).

subarea, the subsidence is gradual and similar in total subsidence values on all points in this subarea (maximum total subsidence $26 \mathrm{~cm}$ ).

We can summarize that the GNSS surveying of the spatial coordinates of the fixed points that was extended by several aerial photogrammetry campaigns enabled to analyze the surface movements in the monitored locality. Evaluation of both vertical and horizontal movements revealed the extent and size of surface changes caused not only by undermining from local mining panels and from exploitation in the surroundings but also by landscape reclamation. It turned out that in the Louky locality with complex geo-mechanical conditions, the subsidence trough develops irregularly and it is significantly influenced by the dominant tectonic fault.

\section{ANALYSES OF SURFACE DEFORMATIONS AND BUILDING SITE CATEGORIZATION}

Significantly uneven development of the subsidence trough can negatively affect constructions in the monitored locality. Therefore it is necessary to pay increased attention not only to movements caused by mining but also to surface deformations.

Thanks to the repeated surveying of the undermined area using the GNSS method, we obtained spatial coordinates of the individual points on the profiles from which the surface deformations can be calculated. We surveyed the points of two line objects: part of $\mathrm{road} \mathrm{II} / 475$, which connects the towns of Havírov and Karviná, and a part of the steam pipeline passing through the observed area. For both these line structures, the magnitude of the deformations is substantial and may affect their functionality.

\section{DEVELOPMENT OF THE BUILDING SITE CATEGORIES ON THE ROAD PROFILE}

The values of terrain deformations of individual line sections between the fixed points on the road profile were computed from the surveyed GNSS data related to the reference surveying at the beginning of the GNSS monitoring. They are presented in graphs B-D in Figure 4 where also the individual building site categories for the given deformation are highlighted: B) Tilt; C) Horizontal strain; D) Radius of curvature. Although the radius of curvature was calculated for all the observed locations along the line, only the values limited to the range of $-22 \leq R \leq 22 \mathrm{~km}$ are depicted in the graph. The point graph was used instead of a linear one for better clarity because the calculated values of radius of curvature differ from $-8917 \mathrm{~km}$ to $30305 \mathrm{~km}$ but only the values of the first tens of kilometers are decisive. Graph A in Figure 4 presents the subsidence curves of the road profile in the individual GNSS surveying campaigns.

From graphs B to D in Figure 4 it is apparent that the most decisive deformation, negatively affecting the line structure, is the tilt which reaches the value of $7.2 \mathrm{~mm} / \mathrm{m}$ on a section with a significantly uneven subsidence, i.e. category III (medium intensity, $8 \geq i>5 \mathrm{~mm} / \mathrm{m}$ ). For horizontal strain, the road profile alternates with the extension and compression of the terrain, and reaches a maximum value of $2.5 \mathrm{~mm} / \mathrm{m}$, i.e. category IV (moderate intensity, $3 \geq \varepsilon>1 \mathrm{~mm} / \mathrm{m}$ ). The radius of curvature reaches a maximum of category IV (moderate intensity, $12 \leq R<20 \mathrm{~km}$ ) but its minimum of $12.4 \mathrm{~km}$ is close to the limit value.

The development of the classification of individual road sections into building site categories is shown in the graph of Figure 7. The final classification into a given category is always decided by the least favorable classification of all three deformations on a given section. The time intervals were chosen according to the exploitation of individual longwall panels and they are related to the reference surveying, i.e. from the reference surveying to the surveying campaign following the end of exploitation of individual longwall panel: a (5.12.2006-3.7.2007), 


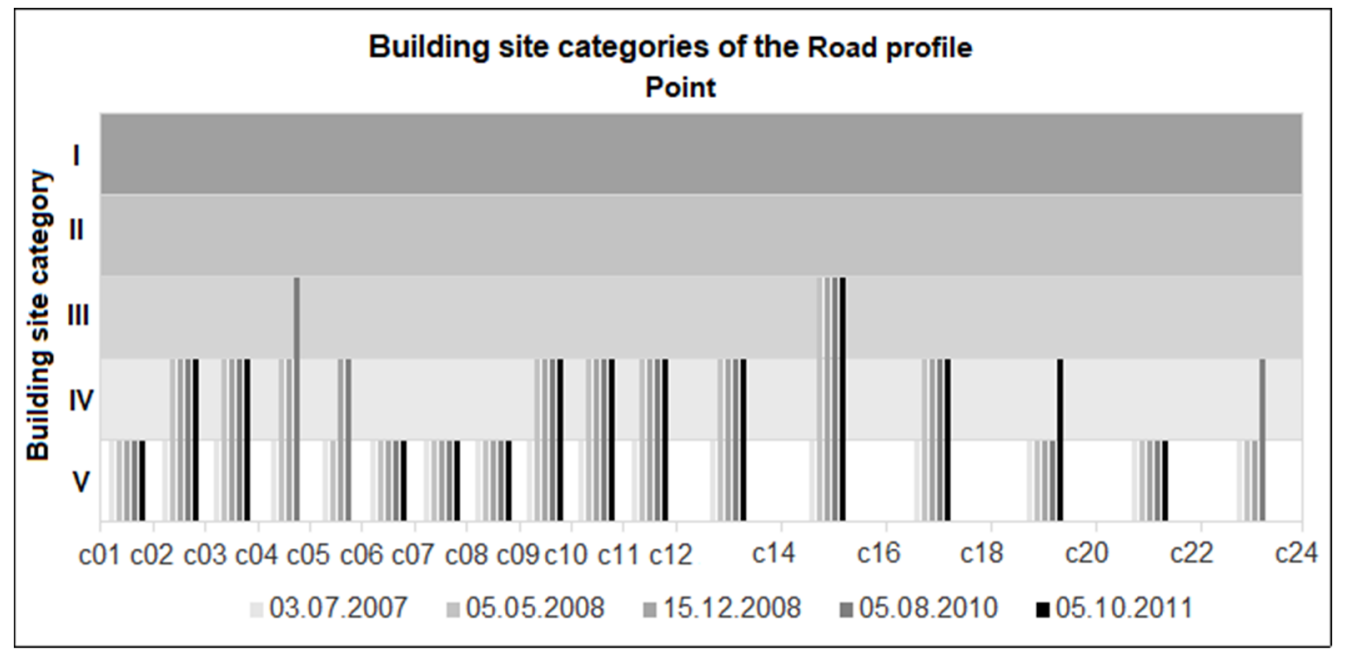

Fig. 7 Building site categories of the road profile.

b (5.12.2006-5.5.2008), pause (5.12.200615.12.2008), $c+d(5.12 .2006-5.8 .2010)$, afterwards (5.12.2006-5.10.2011).

During the mining of the longwall panel $a$, the monitored part of the road is in category $\mathrm{V}$, i.e. a very moderate intensity of the effects of undermining. It is apparent from the subsidence curves that there was an almost uniform subsidence up to $16 \mathrm{~cm}$. The least favorable deformation values are $\varepsilon_{\max }=0.5 \mathrm{~mm} / \mathrm{m}$; $R_{\min }=32 \mathrm{~km} ; i_{\max }=1.1 \mathrm{~mm} / \mathrm{m}$.

During the mining of the longwall panel $b$, some parts of the road fall into category IV, i.e. a moderate intensity of undermining effects, and one section falls into category III, i.e. a medium intensity of undermining effects. It is apparent from the subsidence curves that a subsidence trough begins to form with a center around point $\mathrm{c} 12$ and building site categories worse than $\mathrm{V}$ occur on sections with a steeper slope of the subsidence curve. The maximum subsidence reaches $98 \mathrm{~cm}$, the most significant difference in the magnitude of the subsidence of adjacent points is $49 \mathrm{~cm}$ on section $\mathrm{c} 14-\mathrm{c} 16$. In this case $\varepsilon_{\max }=1.8 \mathrm{~mm} / \mathrm{m}$ (category IV); $R_{\min }=16 \mathrm{~km}$ (category IV); $i_{\max }=5.1 \mathrm{~mm} / \mathrm{m}$ (category III on section c14-c16).

The effects of undermining only slightly deteriorated during the pause after the end of exploitation of longwall panel $b$ from category V to IV on section c05-c06. It is apparent from the course of the subsidence curves that the increase in the subsidence slowed down considerably. The maximum subsidence reaches $105 \mathrm{~cm}$, the most significant difference in the magnitude of the subsidence of adjacent points is $54 \mathrm{~cm}$ on section c14-c16. Here we have $\varepsilon_{\max }=2 \mathrm{~mm} / \mathrm{m}$ (category IV); $R_{\min }=13 \mathrm{~km}$ (category IV); $i_{\max }=5.6 \mathrm{~mm} / \mathrm{m}$ (category III on section c14-c16).

During exploitation of longwall panels $c$ and $d$ (their exploitation was simultaneous for 6 months, therefore it is not possible to distinguish the effect of mining individually), the situation worsened on section c04-c05 where category III is reached and at the end of the road profile on section c22-c24 where category IV is reached. The maximum subsidence of $158 \mathrm{~cm}$ is reached at point $\mathrm{c} 12$, the most significant difference in the magnitude of the subsidence of adjacent points is $70 \mathrm{~cm}$ on section $\mathrm{c} 14-\mathrm{c} 16$. In this case $\varepsilon_{\max }=2.1 \mathrm{~mm} / \mathrm{m}$ (category IV); $R_{\min }=12.4 \mathrm{~km}$ (category IV); $i_{\max }=7.2 \mathrm{~mm} / \mathrm{m}$ (category III on section c14-c16).

After the mining, the points suggest the fading of surface changes. The trend of the subsidence curves is more or less similar. The maximum subsidence reaches $169 \mathrm{~cm}$ (point $\mathrm{c} 12$ ), the most significant difference in the magnitude of the subsidence of adjacent points is $68 \mathrm{~cm}$ on section $\mathrm{c} 14-\mathrm{c} 16$. The least favorable values are $\varepsilon_{\max }=2.5 \mathrm{~mm} / \mathrm{m}$ (category IV); $R_{\min }=12.4 \mathrm{~km} \quad$ (category IV); $i_{\max }=7.2 \mathrm{~mm} / \mathrm{m}$ (category III reached on section c14-c16).

It is obvious that the curves of individual deformations are strongly influenced by a complex geo-mechanical situation. Therefore, it is not appropriate to predict the development of building site categorization and the degree of potential damage to surface constructions in individual parts of the subsidence trough on the basis of theoretical data. The actual development of individual surface deformations will only be shown by surveying. But very often the subsidence is observed as the only indicator of surface changes in the undermined area, only leveling is performed, and then the calculation of terrain deformations is not enabled. However, it is not suitable to judge the size of individual deformations based solely on the course of the subsidence curves, especially in areas with a complex geo-mechanical situation. The following discrepancies are evident when comparing the subsidence curves and the final building site categories of the road profile in the Louky locality: 


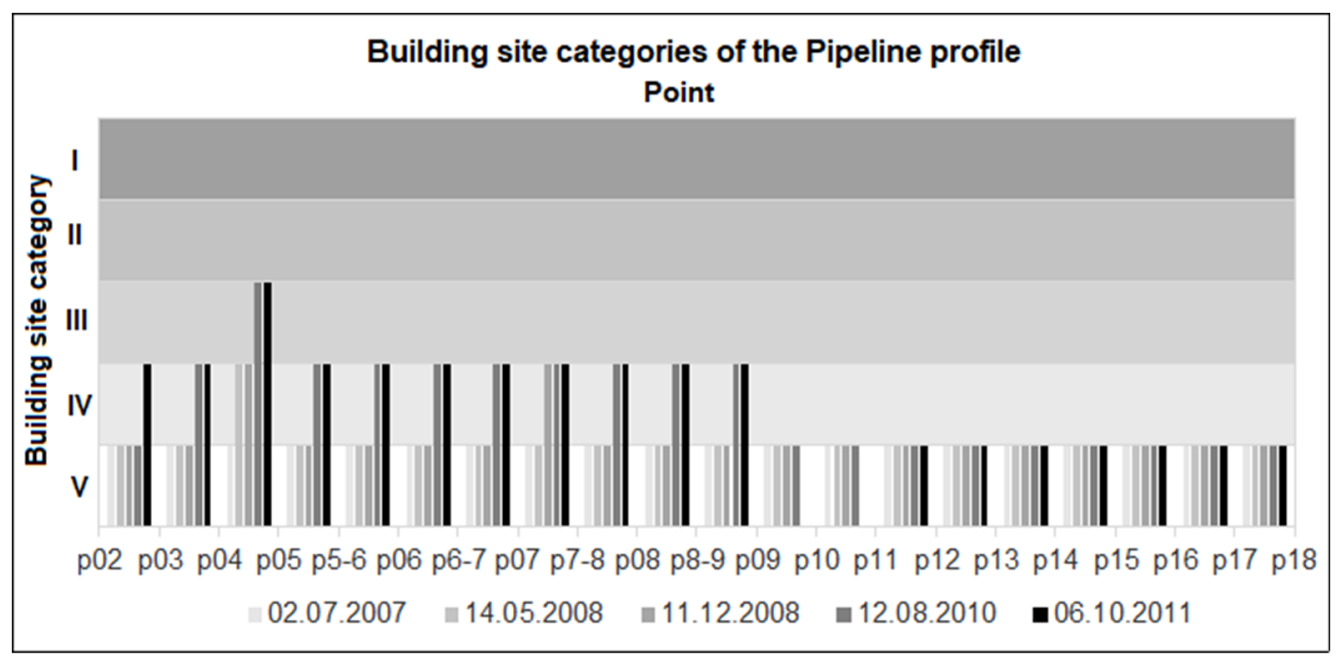

Fig. 8 Building site categories of the pipeline profile.

- $\quad$ Even line sections with subsidence over $1 \mathrm{~m}$ (c06 to $\mathrm{c} 09$ ) are in category $\mathrm{V}$;

- Points at the end subside evenly but the line sections are in different categories (IV vs V);

- End points c18 to c20 subside much less than points $\mathrm{c} 06$ to $\mathrm{c} 09$ but they are in a worse category (IV vs V);

- Section between points c16 and c18 subsiding unevenly is in the same category as the section between points $\mathrm{c} 18$ and c20 that subside equally.

During the surveying, visual observations of the monitored road sections were also performed. It was obvious that the worst damage to the road in the form of cracks with a width of several centimeters repeatedly occurred in the section c14-c16, where category III was reached, i.e. medium intensity of mining impacts. However, significant crack zones with a length of several meters repeatedly occurred also on sections falling into category IV, i.e. moderate intensity of mining impacts. There were also significant changes of the road barriers that were often curved on these sections.

\section{DEVELOPMENT OF THE BUILDING SITE CATEGORIES ON THE PIPELINE PROFILE}

Terrain deformations of individual line sections on the pipeline profile were computed from the surveyed data, related to the reference surveying. They are presented in the graphs B-D in Figure 5, where also the individual building site categories for the given deformation are highlighted: B) Tilt; C) Horizontal strain; D) Radius of curvature (radius of curvature values are limited to the range of $-22 \leq R \leq 22 \mathrm{~km}$ and presented in the point graph).

Again, the most decisive deformation, negatively affecting the line structure, is the tilt which reaches the value of $6.2 \mathrm{~mm} / \mathrm{m}$, i.e. category III (medium intensity, $8 \geq i>5 \mathrm{~mm} / \mathrm{m}$ ). The horizontal strain reaches a maximum value of $1.6 \mathrm{~mm} / \mathrm{m}$, i.e. category
IV (moderate intensity, $3 \geq \varepsilon>1 \mathrm{~mm} / \mathrm{m}$ ). The radius of curvature reaches a maximum of category IV (moderate intensity, $12 \leq R<20 \mathrm{~km}$ ) with its minimum of $13.9 \mathrm{~km}$.

The course of the development of the classification of individual pipeline sections into building site categories is shown in the graph in Figure 8.

The whole monitored part of the pipeline is in category $\mathrm{V}$ during mining of the longwall panel $a$, i.e. very moderate intensity of the effects of undermining. It is apparent from the subsidence curves that there was a slight subsidence to $15 \mathrm{~cm}$. The least favorable deformation values are $\varepsilon_{\max }=0.4 \mathrm{~mm} / \mathrm{m}$; $R_{\min }=36 \mathrm{~km} ; i_{\max }=0.9 \mathrm{~mm} / \mathrm{m}$.

During mining of the longwall panel $b$, only the section p04-p05 on the pipeline falls into category IV, i.e. a moderate intensity of undermining effects. It is apparent from the curves that the subsidence trough begins to form with the center around the point $\mathrm{p} 06$. The maximum subsidence reaches $38 \mathrm{~cm}$, the most significant difference in the magnitude of the subsidence of adjacent points is $15 \mathrm{~cm}$ on section p04- p05. In this case $\varepsilon_{\max }=0.8 \mathrm{~mm} / \mathrm{m}$ (category $\mathrm{V}$ ); $R_{\min }=26 \mathrm{~km}$ (category $\mathrm{V}$ ); $i_{\max }=2.3 \mathrm{~mm} / \mathrm{m}$ (category IV on section p04-p05).

After the end of exploitation of longwall panel $b$, the effects of undermining only slightly worsened from category $\mathrm{V}$ to IV (section p07-p7-8). The maximum subsidence reaches $43 \mathrm{~cm}$, the most significant difference in the magnitude of the subsidence of adjacent points is $16 \mathrm{~cm}$ on section p04-p05. Here we have $\varepsilon_{\max }=0.8 \mathrm{~mm} / \mathrm{m}$ (category $\mathrm{V}$ ); $\quad R_{\min }=25 \mathrm{~km} \quad$ (category $\mathrm{V}$ ); $i_{\max }=2.4 \mathrm{~mm} / \mathrm{m}$ (category IV).

During exploitation of longwall panels $c$ and $d$ the situation deteriorates between points p03 to p09, where 9 sections fall into category IV and category III is reached on section p04-p05. In this case $\varepsilon_{\max }=1.5 \mathrm{~mm} / \mathrm{m} \quad$ (category $\quad \mathrm{IV}$ ); $\quad R_{\min }=16 \mathrm{~km}$ 
(category IV); $i_{\max }=5.6 \mathrm{~mm} / \mathrm{m}$ (category III on section p04-p05).

After the end of exploitation, there is a slight deterioration from category $\mathrm{V}$ to IV only on the first section. The maximum subsidence reaches $98 \mathrm{~cm}$, the most significant difference in the magnitude of the subsidence of adjacent points is $42 \mathrm{~cm}$. The least favorable values are $\varepsilon_{\max }=1.6 \mathrm{~mm} / \mathrm{m}$ (category IV); $R_{\min }=14 \mathrm{~km} \quad$ (category IV); $i_{\max }=6.2 \mathrm{~mm} / \mathrm{m}$ (category III on section p04-p05).

Here, the course of the subsidence curves is more continuous, without sudden changes, and the classification of individual sections into building site categories corresponds with that. But even here, category III is reached on a section located on the slope of the subsidence trough.

\section{DISCUSSION}

Using various surveying and evaluation methods, we can comprehensively assess the surface changes in the monitored locality and discuss their causes. Difficult geo-mechanical conditions of this mining locality proved to be decisive for the movement pattern of the individual undermined points. From the subsidence and horizontal displacements analyses, a notable effect of dominant tectonic fault $A$ on the surface points behavior was found. It was proved that the rate of both subsidence and horizontal displacement of the surface point and its movement direction noticeably depends on the surface point position in the subsidence trough and on the structure and geometry of the tectonic zoning and the degree of failure of the overburden massif (Doležalová et al., 2010).

As expected, the course of individual deformations in the observed locality is influenced by the complex geo-mechanical situation which affected the development of the monitored subsidence trough. While the course of the subsidence curves is continuous at the observed pipeline and the classification of individual sections into building site categories corresponds with that, the road profile shows irregularities. We can see that the conditions for the monitored section of the road remained in category $\mathrm{V}$ after exploitation of longwall panel $a$, but with the exploitation of longwall panel $b$, they deteriorated significantly and even category III was reached. With the exploitation of longwall panels $c$ and $d$, the situation got worse and categories IV and III were found in several sections while some sections with significant subsidence over $1 \mathrm{~m}$ stay in category $\mathrm{V}$. Uneven course or sudden changes in the development of individual surface deformations affects the functionality of the monitored road sections. Significant visible cracks several centimeters wide, repeatedly occurred on some sections of the monitored road which required immediate repair. Dangerous cracks on the road or curved road barriers appeared in sections where categories IV and III were reached, i.e. categories of moderate and medium intensity of mining impacts. The worst deformations occur in the part which is most affected by the dominant fault $A$ but the evaluation of surface deformations also pointed out other risk subareas.

Marschalko et al. (2011) and Lamich et al. (2016) monitored building site categories for a long time on longer road sections in other mining areas of the Karviná region. They recorded a gradual deterioration of surface conditions, and in the long term, even categories I and II were detected in the monitored localities. The authors have shown that monitoring building site categories is a suitable and important tool for planning future development and determination of hazardous zones for foundation engineering purposes. Our case study confirmed this, pointing out subareas where the situation is gradually deteriorating. This, in the case of surface objects such as pipelines or roads, can result in functionality problems. The study might help in future decisions regarding the maintenance and development of the area.

This paper presents the progression of deformations on two surface objects - the pipeline and the road. However, the spatial coordinates of all the fixed points in the Louky locality have been surveyed and thus allow further analysis, e.g. the continuous deformation fields on the surface of the monitored area using geographic information systems (GIS), similar to Blachowski et al. (2014a).

\section{CONCLUSIONS}

The geodetic surveying of the spatial coordinates that allowed to determine both vertical and horizontal movements of the surface points proved to be of the greatest benefit. Especially, the determination of the horizontal movement directions was beneficial for the understanding the processes in the subsidence trough.

Also, the surveying of the spatial coordinates allowed to evaluate the surface deformations and to classify individual sections of the monitored line structures into building site categories according to the values of horizontal strain, radius of curvature and tilt of the terrain. While after the exploitation of longwall panel $a$ all monitored sections of both profiles remained in category $\mathrm{V}$, at the end of the observed period, only $32 \%$ stayed in category $\mathrm{V}$ (very moderate intensity), $49 \%$ fell into category IV (moderate intensity) and $5 \%$ of the profiles' sections fell into category III (medium intensity), $14 \%$ of the sections were not evaluated till the end as their points were destroyed.

Monitoring the development of the building site classification is suitable for permanent maintenance and eventual remediation of line structures in the mining locality and may also be useful for planning the further use of the monitored locality.

In such complex conditions, it is difficult to predict future effects of undermining and to define all the risk subareas in advance. In the part of the Louky locality, where tectonics and other geo-mechanical conditions do not cause uneven development of the subsidence trough, the individual building site 
categories can be suggested from subsidence curves, but in cases where development of the subsidence trough is uneven and the subsidence curves are not continuous and smooth due to complex geo-mechanical conditions, the individual building site categories are difficult to be deduced from the subsidence curves and can be based only on in-situ measurements.

\section{ACKNOWLEDGEMENTS}

This article was supported by a project for the long-term conceptual development of research organizations (RVO: 68145535). The authors would like to thank the anonymous referees for the comments and suggestions that helped to improve the content of the paper.

\section{REFERENCES}

Blachowski, J., Cacoń, S. and Milczarek, W.: 2009, Analysis of post-mining ground deformations caused by underground coal extraction in complicated geological conditions. Acta Geodyn. Geomater., 6, 3(155), 351357.

Blachowski, J., Chrzanowski, A. and Szostak-Chrzanowski, A.: 2014a, Application of GIS methods in assessing effects of mining activity on surface infrastructure. Arch. Min. Sci., 59, 2, 307-321. DOI: 10.2478/amsc-2014-0022

Blachowski, J., Milczarek, W. and Stefaniak, P.: 2014b, Deformation information system for facilitating studies of mining-ground deformations, development, and applications. Nat. Hazards Earth Syst. Sci., 14, 7, 1677-1689. DOI: 10.5194/nhess-14-1677-2014

Bogusz, M. and Mendecki, M.: 2011, Seismic and geodetic observations of subsidence trough development over a longwall face in a coal bed under extraction. In: Idziak, A.F. and Dubiel, R. (Eds): Geophysics in Mining and Environmental Protection. Geoplanet: Earth and Planetary Sciences, 71-79. DOI: $10.1007 / 978-3-642-19097-17$

Bräuner, G.: 1994, Rockbursts in coal mines and their prevention. Balkema, Rotterdam, 144 pp.

Budryk, W. and Knothe, S.: 1956, The principles of classification of the Upper Silesian Industrial District areas with regard to possibility of their using for construction development. Biuletyn nr 4, PAN Komitet ds. GOP, Warszawa, (in Polish).

Can, E., Kuscu, S. and Mekik, C.: 2012, Determination of underground mining induced displacements using GPS observations in Zonguldak-Kozlu Coal Basin. Int. J. Coal Geol., 89, 62-69. DOI: 10.1016/j.coal.2011.08.006

Chen, B., Li, Z., Yu, C., Fairbairn, D., Kang, J., Hu, J. and Liang, L.: 2020, Three-dimensional time-varying large surface displacements in coal exploiting areas revealed through integration of SAR pixel offset measurements and mining subsidence model. Remote Sens. Environ., 240, 111663. DOI: $10.1016 /$ j.rse.2020.111663

Černý, I. et al.: 2003, Coal mining in Ostrava-Karvina region. Anagram, Ostrava, 564 pp., (in Czech).
ČSN 73 0039: 2015, Design of constructions on the mining subsidence areas. Standard ČSN. Basic Regulations, (in Czech).

Doležalová, H.: 2011, Suggestion of complex monitoring of undermined territory. In: Idziak, A.F. and Dubiel, R. (Eds), Geophysics in Mining and Environmental Protection. Geoplanet: Earth and Planetary Sciences, 81-89. DOI: $10.1007 / 978-3-642-19097-18$

Doležalová, H. and Kajzar, V.: 2017, Prediction of subsidence depression development. Systemy Wspomagania w Inżynierii Produkcji, 6, No. 4, 208214.

Doležalová, H., Kajzar, V., Souček, K. and Staš, L.: 2009, Evaluation of mining subsidence using GPS data. Acta Geodyn. Geomater., 6, 3(155), 359-367.

Doležalová, H., Kajzar, V., Souček, K. and Staš, L.: 2010, Evaluation of vertical and horizontal movements in the subsidence depression near Karviná. Acta Geodyn. Geomater., 7, 3(159), 355-361.

Doležalová, H., Kajzar, V., Souček, K. and Staš, L.: 2012, Analysis of surface movements from undermining in time. Acta Geodyn. Geomater., 9, 3(167), 389-400.

Dopita, M. et al.: 1997, Geology of the Czech part of Upper Silesian Basin. Ministry of the Environment of the Czech Republic, Praha, 278 pp., (in Czech).

Dulias, R.: 2016, The impact of mining on the landscape. A study of the Upper Silesian Coal Basin in Poland. Springer, Switzerland, 209 pp. DOI: $10.1007 / 978-3-319-29541-1$

Hiramatsu, Y., Okamura, H. and Sugawara, K.: 1979, Surface subsidence and horizontal displacement caused by mining inclined coal seams. In: Proc. 4th Congress International Society for Rock Mechanics, Balkema, Rotterdam, 665-670.

Idziak, A.F.: 1999, A study of spatial distribution of induced seismicity in the Upper Silesian Coal Basin. Nat. Hazards, 19, 2-3, 97-105.

DOI: 10.1023/A:1008089931203

Jiránková, E.: 2012, Utilisation of surface subsidence measurements in assessing failures of rigid strata overlying extracted coal seams. Int. J. Rock Mech. Min. Sci., 53, 111-119.

DOI: 10.1016/j.ijrmms.2012.05.007

Kadlečík, P., Kajzar, V., Nekvasilová, Z., Wegmüller, U. and Doležalová, H.: 2015, Evaluation of the subsidence based on DInSAR and GPS measurements near Karviná, Czech Republic. Acta Univ. Carol. Geogr., 50, 1, 51-61. DOI: $10.14712 / 23361980.2015 .86$

Kajzar, V.: 2018, Geodetic and seismological observation applied for investigation of subsidence formation in the CSM Mine (Czech Republic). Mining of Mineral Deposits, 12, No. 2, 34-46.

DOI: $10.15407 / \operatorname{mining} 12.02 .034$

Kajzar, V. and Doležalová, H.: 2013, Monitoring and analysis of surface changes from undermining. Geoscience Engineering, 59, No. 4, 110.

Kajzar, V., Doležalová, H., Souček, K. and Staš, L.: 2011, Aerial photogrammetry observation of the subsidence depression near Karviná. Acta Geodyn. Geomater., 8, 3(163), 309-317.

King, H.J., Whittaker, B.N. and Shadbolt, C.H.: 1974, Effects of mining subsidence on surface structures. In: Jones, M.J. (Ed.), Mining and the Environment. 
Institution of Mining and Metallurgy, London, 617642.

Knothe, S.: 1953, Equation of the subsidence trough asymptotic profile. Archives Mining and Metallurgy, 1, 111-127, (in Polish).

Knothe, S.: 1984, Prediction of mining influence. Śląsk Publishing House, Katowice, 160 pp., (in Polish).

Kratzsch, H.: 1983, Mining subsidence engineering. Springer, Berlin, $546 \mathrm{pp}$.

Lamich, D., Marschalko, M., Yilmaz, I., Bednářová, P., Niemiec, D., Mikulenka, V. and Kubečka, K.: 2016, Geodetic monitoring of roads as a tool for determination of hazard zones in areas influenced by deep coal mining. Bull. Eng. Geol. Environ., 75, 3, 1033-1044. DOI: 10.1007/s10064-015-0769-y

Leica: 2007, GPS1200 Series Technical Data

Malinowska, A. and Hejmanowski, R.: 2010, Building damage risk assessment on mining terrains in Poland with GIS application. Int. J. Rock Mech. Min. Sci., 47, 2, 238-245. DOI: 10.1016/j.jirmms.2009.09.009

Mark, C. and Gauna, M.: 2016, Evaluating the risk of coal bursts in underground coal mines. Int. J. Min. Sci. Technol., 26, 1, 47-52. DOI: $10.1016 /$ j.ijmst.2015.11.009

Marschalko, M., Yilmaz, I.C., Bednárik, M. and Kubečka, K.: 2011, Variations in the building site categories in the underground mining region of Doubrava (Czech Republic) for land use planning. Eng. Geol., 122, 3-4, 169-178. DOI: 10.1016/j.enggeo.2011.05.008

Miller, B.G.: 2011, Clean Coal Engineering Technology. Butterworth-Heinemann, Oxford, $696 \mathrm{pp}$.

Muntean, A., Mocanu, V. and Ambrosius, B.: 2016, A GPS study of land subsidence in the Petrosani (Romania) coal mining area. Nat. Hazards, 80, 2, 797-810. DOI: 10.1007/s11069-015-1997-y

Neset, K.: 1984, Effects of undermining. SNTL, Praha, 344 pp., (in Czech).

OKD, a.s.: 2010, Ostrava-Karvina Mines, Internal reports.

Ostrowski, J. and Ćmiel, A.: 2008, The use of a logit model to predict the probability of damage to bullding structures in mining terrains. Arch. Min. Sci., 53, 2, $161-182$.
Perski, Z. and Jura, D.: 1999, ERS SAR interferometry for land subsidence detection on coal mining areas. Earth Obser. Quart., 63, 25-29.

Perz, W.: 1957, Observations of subsidence over underground workings in the Austrian Tertiary Coal Basins. In: Proc. European Congress on Ground Movement, University of Leeds, 92-98.

Popiołek, E.: 2009, Protection of mining areas. AGH, Kraków, 297 pp, (in Polish).

Przybyła, H. and Świądrowski, W.: 1968, Determination of resistance category of existing public housing to the influence of mining. OTG, Katowice, (in Polish).

Schenk, J.: 1999 Measurement of movements and deformations in the subsidence trough. VŠB-TUO, Ostrava, 144 pp., (in Czech).

Sheorey, P.R., Singh, K.B., Singh, S.K. and Loui, J.P.: 2000, Ground subsidence observations and a modified influence function method for complete subsidence prediction. Int. J. Rock Mech. Min. Sci., 37, 801-818.

Sroka, A., Popiołek, E. and Hejmanowski, R.: 1994, Probabilistic method to assess risk for construction works caused by underground mining operations. Bezpieczeństwo Pracy i Ochrona Środowiska w Górnictwie, 1, 55-60.

Staš, L., Kajzar, V., Doležalová, H., Souček, K., Smetanová, L. and Georgiovská, L.: 2009, GPS monitoring of subsidence depression progress on undermined area. In: Nowoczesne metody eksploatacji węgla i skał zwięzłych. AGH, Kraków, 99-106.

Strzałkowski, P.: 2001, New mathematical model for description of time-dependent surface subsidence. Trans. Inst. Min. Metall., Section A: Mining Technology, 110, A178-A182.

Wesołowski, M.: 2016, Numerical modeling of exploitation relics and faults influence on rock mass deformations. Arch. Min. Sci., 61, 4, 893-906. DOI: $10.1515 /$ amsc-2016-0059

Whittaker, B.N. and Reddish, D.J.: 1989, Subsidence: Occurrence, prediction and control. Elsevier, Amsterdam, 528 pp. 